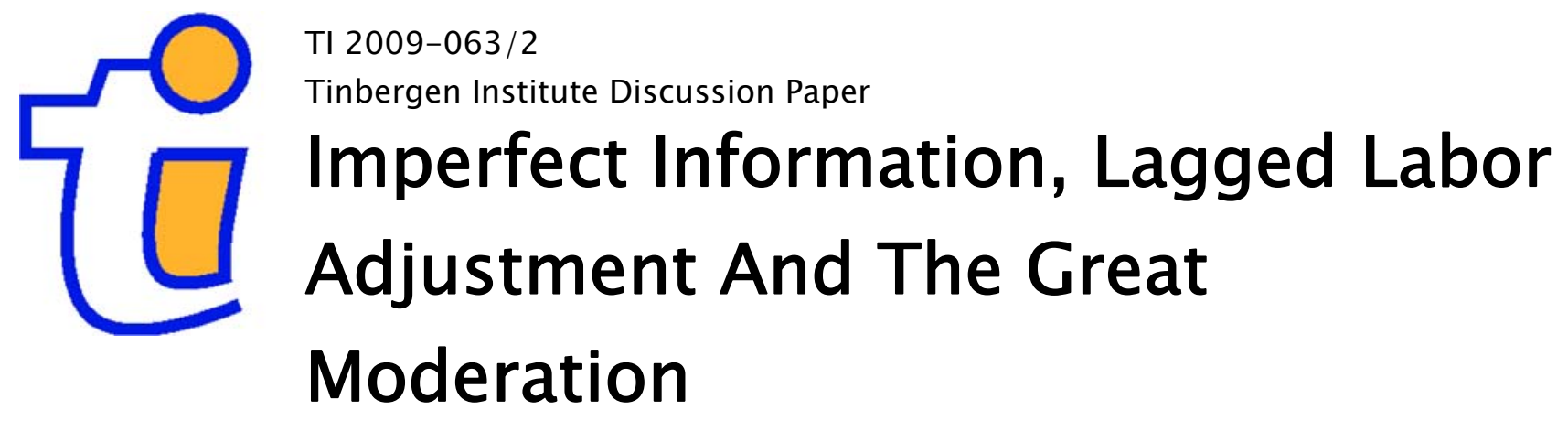

Tim Willems

Sweder van Wijnbergen*

University of Amsterdam.

* Tinbergen Institute 


\section{Tinbergen Institute}

The Tinbergen Institute is the institute for economic research of the Erasmus Universiteit Rotterdam, Universiteit van Amsterdam, and Vrije Universiteit Amsterdam.

Tinbergen Institute Amsterdam

Roetersstraat 31

1018 WB Amsterdam

The Netherlands

Tel.: +31(0)205513500

Fax: $+31(0) 205513555$

Tinbergen Institute Rotterdam

Burg. Oudlaan 50

3062 PA Rotterdam

The Netherlands

Tel.: + $31(0) 104088900$

Fax: $+31(0) 104089031$

Most TI discussion papers can be downloaded at http://www.tinbergen.nl. 


\title{
Imperfect information, lagged labor adjustment and the Great Moderation
}

\author{
Tim Willems and Sweder van Wijnbergen*
}

April 18, 2012

\begin{abstract}
This paper first documents the increase in the lag with which US labor input reacts to structural shocks since the 1980s. We show that lagged labor adjustment is optimal when there is uncertainty about the persistence of shocks and labor input is costly to adjust. We then present evidence that both the nature of shocks hitting the economy as well as labor adjustment costs have changed during the 1980s in a direction that could explain the increase in the lag. Finally, we show that this development has the potential to explain both the reduction in the procyclicality of labor productivity as well as that in output volatility since the 1980s.
\end{abstract}

JEL: E24, E32, J23, J24

Keywords: imperfect information, labor adjustment, jobless growth, option value of waiting, Great Moderation

${ }^{*}$ Willems: University of Amsterdam, Valckenierstraat 65-67, 1018 XE Amsterdam, The Netherlands, t.willems@uva.nl. Van Wijnbergen: University of Amsterdam and Tinbergen Institute, Valckenierstraat 65-67, 1018 XE Amsterdam, The Netherlands, s.j.g.vanwijnbergen@uva.nl. We thank Eric Bartelsman, Wouter den Haan, Kristoffer Nimark, Thijs van Rens and Petr Sedlacek for useful comments and discussions as well as seminar participants at the Tinbergen Institute, Tilburg University and the University of Groningen. Any errors are of course ours. 


\section{Introduction}

Contrary to previous ones, the last three economic recoveries (starting in 1991, 2001, and the current one in 2009) were not accompanied by a simultaneous increase in employment. Although there is a name for this phenomenon ("jobless growth"), there is no agreement yet on its roots. Besides jobless recoveries, the 1990s and 2000s also brought recessions that had a rather delayed negative effect on labor input. These two observations suggest that firms have become more cautious in adjusting labor input over the years and that the lag with which labor input reacts to business cycle fluctuations ("the labor adjustment lag") went up in the 1980s. The documentation, causes, and consequences of this lag lie at the heart of this paper.

To explain this lagged response of labor input, we propose a theory based on the option value of waiting. The real options literature suggests that there exists an option value to waiting in a stochastic imperfect information setting when the initial costs of investment are at least partially sunk ( $c f$. Dixit and Pindyck (1994), who apply the real options concept to investment decisions). We show that the concept can equally fruitfully be applied to labor markets. After all, in the presence of labor adjustment costs, hiring and firing decisions also become costly to undo. We show that it is then optimal for employers to respond sluggishly to shocks, as the positive option value to waiting induces them to gather more information on the nature of the shock (persistent or transitory?), before making hiring and firing decisions. As a result, the labor input cycle will lag the business cycle.

The outline of this paper is as follows: in Section 2, we illustrate the emergence of the labor adjustment lag in the mid 80s, after which Section 3 discusses the literature on it. In Section 4 we construct a simple two period model, designed to highlight the option value of waiting in a setting with imperfect information on the persistence of shocks and labor adjustment costs. In Section 5 we present an analysis of the model focusing on the interaction between labor adjustment costs and imperfect information. Section 6 shows that both informational imperfections and labor adjustment costs are necessary to trigger a lagged labor input response. In Section 7, we answer the empirical question why the labor adjustment lag has 
increased in the 1980s. Subsequently, Section 8 shows how the lengthening of the labor adjustment lag can explain several recent macroeconomic puzzles, such as the Great Moderation and the vanishing procyclicality of labor productivity. Finally, Section 9 concludes.

\section{The labor adjustment lag}

\subsection{Raw data}

All recoveries before the 1990/1 recession were accompanied by a much quicker increase in the number of people employed than the three subsequent recoveries. This is shown in Fig. 1, which displays the employment level several months before and after the start of the recovery ("the trough", indicated by the vertical line), relative to the level of employment at the trough, for the average pre-1990 recession, as well as for the recessions of 1990/1, 2001, and 2007/9. ${ }^{1}$ Clearly, employment showed a much more delayed response to the last three recoveries than before. ${ }^{2}$

But Fig. 1 shows more: the last three recoveries were not just "jobless", but employment actually continued to fall - even when production was on the rise again. After the troughs in 1991 and 2009, employment for example continued to fall for about a year. This is even clearer for the 2001 recession, where employment reached its trough only 1.5 years after output did. Apparently, employers did not manage to adjust their labor input according to their likings within the recessionary period, which suggests that they have also become more cautious in decreasing labor input in recessionary times.

\footnotetext{
${ }^{1}$ This section uses the NBER postwar trough dates being: October 1949; May 1954; April 1958; February 1961; November 1970; March 1975; July 1980; November 1982; March 1991; November 2001; June 2009.

${ }^{2}$ These seasonally adjusted, monthly employment data are taken from the St. Louis Fed database and contain total nonfarm payrolls. As dispersion around the average pre-1990 line is small, we only display the average.
} 


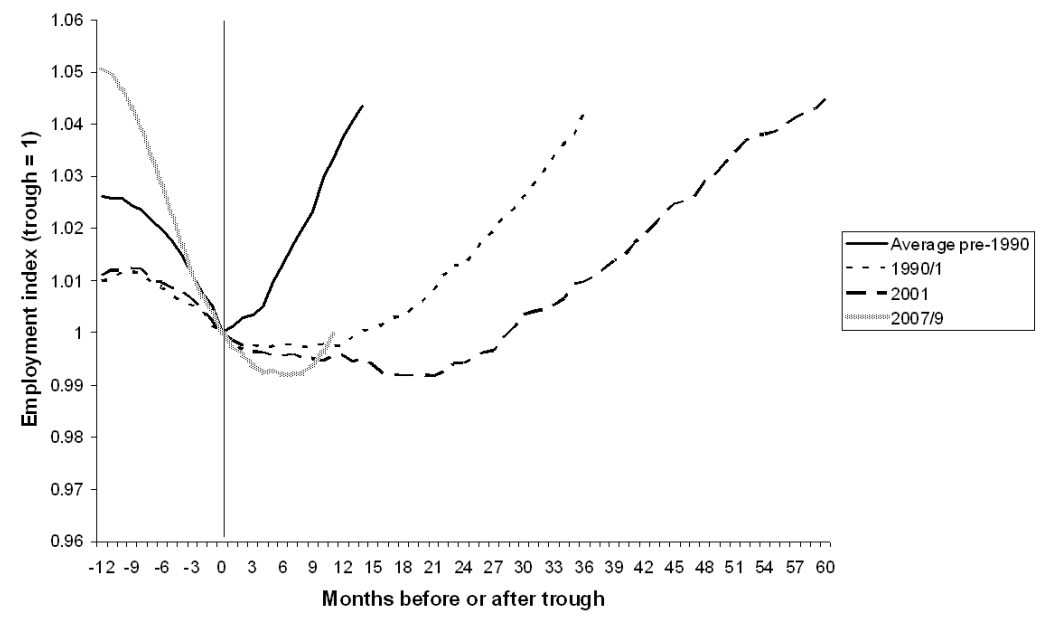

Fig. 1. Employment over the cycle

Clearly, the lack of an employment response on the extensive margin could have been offset by labor input changes on the intensive margin of hours worked. However, from Fig. 2 it is apparent that such a substitution has not taken place. ${ }^{3}$

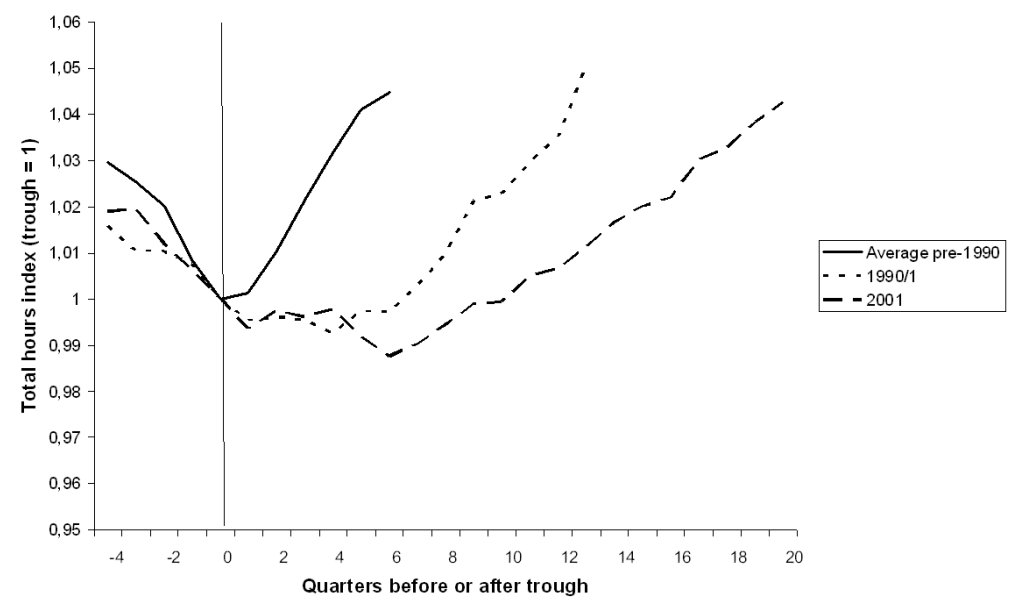

Fig. 2. Total hours worked over the cycle

\footnotetext{
${ }^{3}$ The underlying BLS-based data on total hours worked are taken from Francis and Ramey (2009). In contrast to standard BLS-data, they contain the number of hours worked in the total economy (rather than the number of hours worked in the private business sector). Unfortunately, they are only available at a quarterly frequency and do not cover the 2007/9 recession. Again, dispersion around the pre-1990 line is small.
} 
Figure 3 shows that the change in labor input dynamics has had a clear impact on the path followed by total output around recessions: all post-1990 recoveries are much weaker than their predecessors. ${ }^{4}$

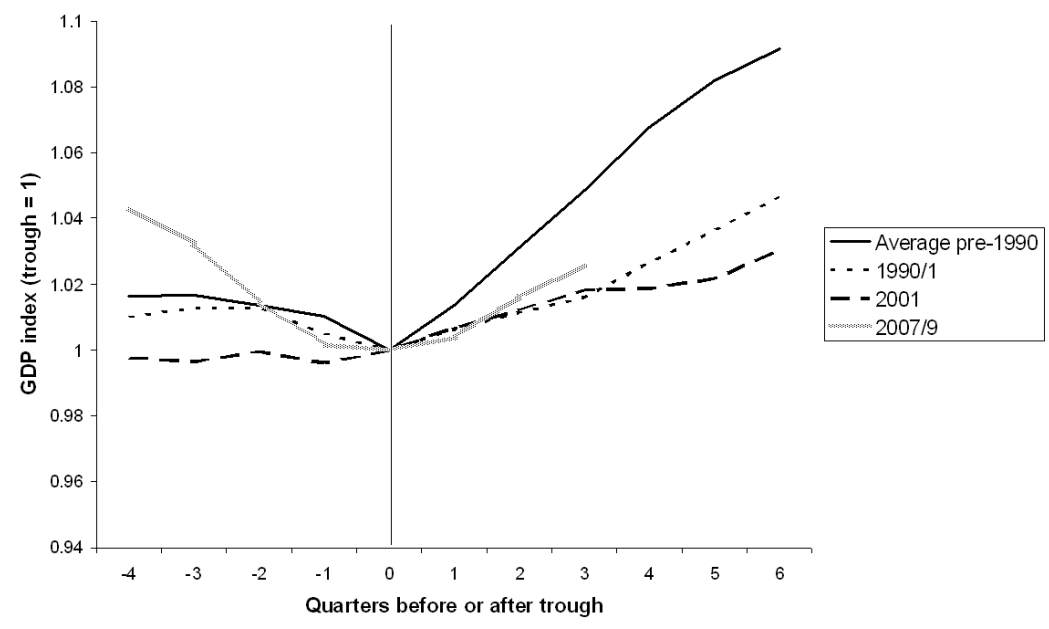

Fig. 3. Real GDP over the cycle

Given the changed behavior of labor input, this is not surprising: after all, since the 1980s an autonomous increase in real GDP (for example due to a positive productivity shock) is no longer accompanied by an almost simultaneous increase in labor input so that output shows a weaker response.

The raw data thus suggest that labor input responds with a greater lag to shocks that drive GDP-fluctuations since the 1980s. In the next section, we will investigate this conjecture econometrically by looking at estimated impulse response functions of labor input to the structural shocks that drive output fluctuations.

\subsection{Labor adjustment in response to structural shocks}

We identify the structural shocks by imposing long run restrictions as in Blanchard and Quah (1989). We define a vector $Y \equiv(\Delta l p, h)^{\prime}$, where $\Delta l p$ is the quarterly change in the natural log of labor productivity (output per hour worked in the nonfarm business sector, taken from the BLS) and $h$ is the natural log of the number of

\footnotetext{
${ }^{4}$ These seasonally adjusted data on real GDP are taken from the St. Louis Fed.
} 
hours worked per capita over the age of 16 (again from Francis and Ramey (2009)). ${ }^{5}$ The vector $\varepsilon=\left(\varepsilon_{t}^{T}, \varepsilon_{t}^{N T}\right)^{\prime}$ describes the two structural shocks: technology $(T)$ and non-technology $(N T)$ ones. The vector $Y$ can then be expressed as a distributed lag of both of these shocks:

$$
\left[\begin{array}{c}
\Delta l p_{t} \\
h_{t}
\end{array}\right]=\left[\begin{array}{cc}
A_{11}(L) & A_{12}(L) \\
A_{21}(L) & A_{22}(L)
\end{array}\right]\left[\begin{array}{c}
\varepsilon_{t}^{T} \\
\varepsilon_{t}^{N T}
\end{array}\right] \Leftrightarrow Y_{t}=A(L) \varepsilon_{t}
$$

Here, the assumption that the structural shocks are orthogonal to each other, together with a standard normalization, implies that $\mathbb{E} \varepsilon_{t} \varepsilon_{t}^{\prime}=I$. It is possible to identify both shocks by assuming (as in Galí (1999)) that technology shocks are the only ones to affect the level of labor productivity in the long run. This restriction requires the matrix $A(1)$ to be lower triangular (i.e. $A_{12}(1)=0$; see Blanchard and Quah (1989) for details). Having identified the shocks in this way, the second row of the $A$-matrix gives us the impulse response functions (IRFs) of labor input to both technology and non-technology shocks. Figs 4 and 5 display these. ${ }^{6}$

As can be seen from Fig. 4, the persistence in the labor input response to a technology shock went up over time: since 1984, a much bigger share of total labor adjustment is made at longer lags. Moreover, the post- 84 response is also much more lagged, reaching its peak only after 11 quarters (against 6 quarters for the pre-84 response).

\footnotetext{
${ }^{5}$ Note that this structure differs from the one in Galí (1999) for the reasons explained in Christiano et al. (2003). The consequences of choosing either specification are not innocent, for other reasons than of interest to the current paper: using Galí's (1999) specification, one finds that hours worked fall after a technology shock, while the level-specification results in a positive response. However, whether hours worked rise or fall after a technology shock is not essential for our theory; what is essential, is that agents in the economy are uncertain about the persistence of shocks that drive the business cycle. Whether they occur at the supply or demand side is not important.

${ }^{6}$ Both figures are based upon a $V A R(4)$, where the lag length was selected via Akaike's information criterion. The underlying data run from 1948Q1 to 2009Q2. The break points are chosen such that the recovery from the 1982 recession still is included in the first sample, while the recessions with jobless recoveries are included in the second sample. Both graphs are robust to picking any other break point in the 1982-1989 interval.
} 


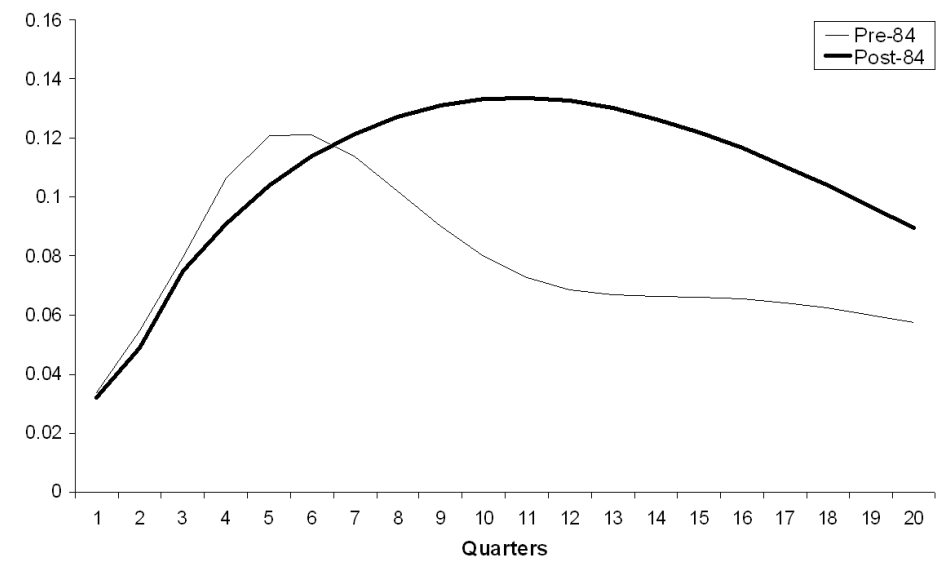

Fig. 4. Impulse response functions of total hours to a technology shock

Figure 5 shows the IRFs to a non-technology shock. As can be seen from the figure, the post- 84 response is much more muted and lagged: whereas the pre-1984 IRF has a sharp peak after three quarters already, the post- 84 response is characterized by a much more gradual build-up and needs ten quarters to reach its maximum.

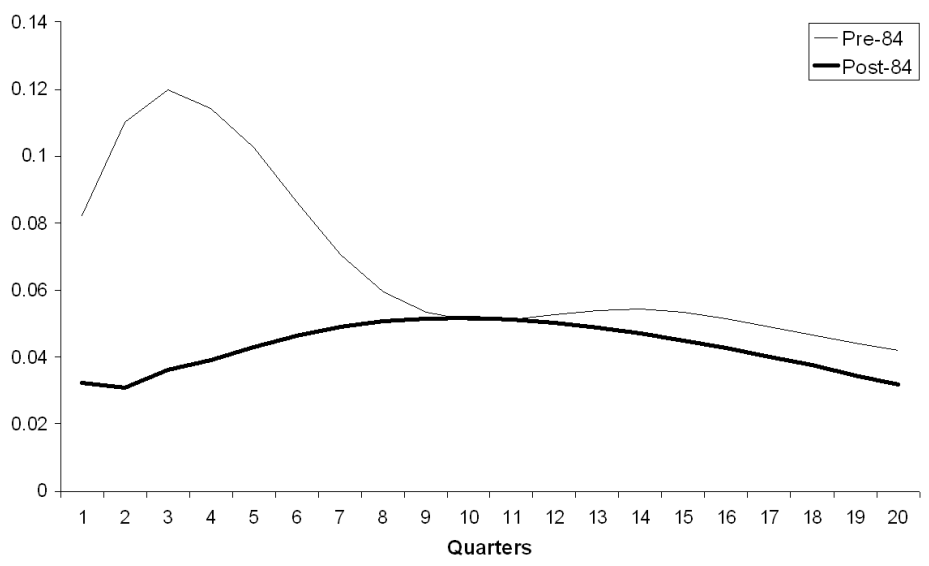

Fig. 5. Impulse response functions of total hours to a non-technology shock

\subsection{Summing up}

We presented evidence that the lag with which labor input is adjusted in response to structural economic shocks went up somewhere in between the 1982 recovery and 
the one starting in 1991. The lag is present at the extensive margin and robust to including the intensive margin. Hence, the increase in this lag is not the result of an increased reliance of employers to adjust labor input on the hours margin. This confirms recent findings that the intensive margin is less important than the extensive one for changing labor input in the US. ${ }^{7}$ Therefore, we will abstract from the hours-margin and focus at the extensive margin instead in the remainder of the paper.

\section{Related literature}

The wide attention that the labor adjustment lag and jobless growth have received in the media, has to date not been matched by comparable academic interest. So far, only a few papers have dealt with this issue. First, Groshen and Potter (2003) have pointed at the role played by sectoral reallocation. They explain the occurrence of jobless recoveries by hypothesizing that the changing economic environment over the last decades has forced workers into time consuming career changes. The problem with their explanation is however that sectoral reallocation has actually declined since the 1980s (Aaronson, et al. 2004), which suggests that another explanation is needed.

Andolfatto and MacDonald (2004) attribute jobless growth to the fact that new technologies impact different sectors of the economy unevenly and are slow to diffuse. But there is no evidence that the impact of innovations suddenly changed somewhere between the last "job driven" recovery in 1982 and the first jobless-one in 1991, as a result of which their theory cannot explain this remarkable difference.

In Bachmann's (2009) DSGE-model, employers can generate a jobless recovery by adjusting their labor input along the intensive margin. However, Fig. 2 above shows that this does not explain the jobless recoveries the US has witnessed, as they did not show an increase in the total number of hours worked either.

Finally, Van Rens (2004) and Koenders and Rogerson (2005) relate jobless growth

\footnotetext{
${ }^{7}$ See for example Gertler et al. (2008) who estimated a Frisch-elasticity of zero for the intensive margin.
} 
to organizational issues within firms. Both of these theories however predict that jobless recoveries will only follow after long expansions, which seems inconsistent with the jobless recovery to the $2007 / 9$ recession (which was not preceded by an unusually long expansion).

Bentolila and Bertola (1990) are conceptually closer to us. They also stress option values for firms in the presence of labor adjustment costs: hiring for example implies that a firm gives up the call option to delay the hiring decision. Through this mechanism, they show that labor adjustment costs lower the volatility of the level of employment - a result that is contained by our model ( $c f$. Section 6). Contrary to the current paper, Bentolila and Bertola (1990) however do not touch upon the role played by imperfect information as a result of which they do not establish the link with lagged labor adjustment. The jobless growth question thus remains unexplained in the existing literature.

\section{Model}

As in Van Wijnbergen (1985, who applies the idea of the option value of waiting to trade reform issues), we analyse the problem in a simple two period setup.

The structure of the model is as follows: the model is populated by a large pool of potential employees (sufficiently large to prevent the stock of employees from becoming a binding constraint) along with a large number of small firms (each too small to affect prices in the economy).

At the beginning of period 1 the economy is hit by a positive productivity shock: the level of productivity unexpectedly rises from $A_{0}=A$ to $A_{1}=A+\xi{ }^{8}$ After the occurrence of this shock, firms and workers engage in a bargaining game to decide upon the employment contract. As in Dowrick (1989), among others, the latter determines the level of employment and the wage rate. In the subsequent production stage, each firm produces according to the following production function:

$$
Y_{t}=A_{t} N_{t}^{\alpha}
$$

\footnotetext{
${ }^{8}$ Every statement in the paper applies mutatis mutandis to negative productivity shocks.
} 
Here $\alpha \in(0,1)$ captures the decreasing returns to labor. We abstract from capital accumulation, as the impact of uncertainty on investment has been extensively covered in the literature and is not material to the short-run jobless growth issue we focus on. Output is sold in a competitive goods market at a price normalized to one.

When the productivity shock $\xi$ materializes in period 1 , it is however not immediately clear whether this shock is permanent or transitory. This will only become clear at the beginning of period 2 when $A_{2}$ materializes. In particular, with exogenous probability $\theta$ (which is known to the rational agents in the model) the shock is fully persistent which implies that $A_{2}=A+\xi$. However, there is a probability $(1-\theta)$ that the shock was purely transitory in which case $A_{2}=A$ again. In this way, we model the fact that agents are uncertain about the duration of booms and recessions; only by observing next period's state, they obtain more information about the persistence of a shock.

Without loss of generality, we assume that there is no discounting. The firm's profit function over both periods then reads:

$$
\Pi=A_{1} N_{1}^{\alpha}-w_{1} N_{1}+\mathbb{E}_{1}\left\{A_{2} N_{2}^{\alpha}-w_{2} N_{2}\right\}
$$

Here, $\mathbb{E}_{1}$ is the expectations operator conditioned on all information available at $t=1$ and $w_{1}\left(w_{2}\right)$ is the wage rate prevailing at $t=1(2)$. As noted before, this wage rate will be determined endogenously (along with the level of employment) through Nash-bargaining between firms and workers (who are assumed to bargain collectively via firm-specific worker unions). Following the labor literature, firms and workers enter this bargaining process with equal bargaining weights of 0.5. Moreover, firms are assumed to have a zero outside option (the value of closing down), while the outside option of the workers is given by $b$ (which can be thought of as the combined value to leisure, home production and unemployment benefits). The bargaining solution then follows from:

$$
\max _{\{N, w\}} S=F^{0.5} W^{0.5}
$$


where $F$ is the bargaining surplus for firms, which is given by firm profits:

$$
F=\Pi \text {, }
$$

and with $W$ being the bargaining surplus for all employed workers over their outside option $b$ :

$$
W=N_{1}\left(w_{1}-b\right)+N_{2}\left(w_{2}-b\right)
$$

We then add the informational imperfection and costly labor adjustment. To identify the separate contributions of each of these elements, we develop a simple and flexible framework which allows us to add the two frictions one-by-one. This leads to four cases that are to be considered. First, we will analyse the benchmark case in which there are no labor adjustment costs and where the employer has full flexibility in choosing his labor input (Case I). In this setting, the employment level can costlessly be reset at the beginning of period 2, after the nature of the shock has been revealed. Subsequently, we will introduce a role for the informational imperfection in Case II by considering the situation in which the employer has to pre-commit. In this setting, he must set both his first- and second-period level of employment in period 1 already. Hence, at the time of his decision, he does not know yet whether the shock is persistent or not. Next, we will add labor adjustment costs. Motivated by the available empirical evidence (see e.g. Hamermesh and Pfann (1996) and Bloom (2009)), we model labor adjustment costs in a non-convex way. Maintaining the assumption that there is imperfect information on the persistence of shocks, Case III considers the limiting case in which the employer loses the opportunity to adjust his labor input at the beginning of the second period. Effectively, this represents infinite, non-convex labor adjustment costs. Finally, we will also consider the remaining case (Case IV) in which there are infinite, non-convex labor adjustment costs, but where employers are perfectly able to distinguish persistent shocks from transitory ones.

Using this model, we will demonstrate two points. First, Proposition 1 will show that the ability to defer decisions until more information has arrived carries an option value. Subsequently, Proposition 2 will indicate under what sort of assumptions on adjustment costs and information availability this option value will actually generate 
delayed hiring and firing decisions.

\section{The cases}

\subsection{Case I: flexibility, no labor adjustment costs}

In this case, the period 1 levels of wages and employment are determined via the bargaining game that takes place directly after the occurrence of the shock. However, when doing this, both firms and workers realize that they will get the opportunity to reset employment and wages costlessly at the beginning of period two, after the nature of the shock has been revealed. Consequently, the informational imperfection is not binding (as a result of which the distinction between perfect/imperfect information does not make any difference for this case) and the problem reduces to solving two independent static optimization problems. In this setting, the second period bargaining surpluses conditional upon $A_{2}$ read:

$$
\begin{aligned}
F_{2}^{f}\left(A_{2}\right) & =A_{2}\left(N_{2}^{f}\right)^{\alpha}-w_{2} N_{2}^{f} \\
W_{2}^{f}\left(A_{2}\right) & =N_{2}^{f}\left(w_{2}^{f}-b\right),
\end{aligned}
$$

where the superscript $f$ indicates that these are the values under flexibility, while the subscript 2 refers to the fact that we are only looking at the second period.

The first-order conditions associated with the Nash-bargaining process then read:

$$
\begin{aligned}
& \frac{\partial S_{2}^{f}}{\partial N_{2}^{f}}=0 \Leftrightarrow 0.5\left[\frac{W_{2}^{f}}{F_{2}^{f}}\right]^{0.5}\left[\alpha A_{2}\left(N_{2}^{f}\right)^{\alpha-1}-w_{2}\right]+0.5\left[\frac{F_{2}^{f}}{W_{2}^{f}}\right]^{0.5}\left[w_{2}-b\right]=0 \\
& \frac{\partial S_{2}^{f}}{\partial w_{2}^{f}}=0 \Leftrightarrow W_{2}^{f}=F_{2}^{f}
\end{aligned}
$$

Inserting the second first-order condition into the first one, tells us that:

$$
N_{2}^{f}\left(A_{2}\right)=\left[\frac{\alpha A_{2}}{b}\right]^{\frac{1}{1-\alpha}}
$$


Given the employer's optimal response in period 2 (represented by eq. (1)), solving the equivalent problem for the first period yields: ${ }^{9}$

$$
N_{1}^{f}=\left[\frac{\alpha(A+\xi)}{b}\right]^{\frac{1}{1-\alpha}}
$$

Note that the period 1 level of employment is independent of $\theta$, the probability that the shock survives into the second period. This is because the case under consideration allows for a renegotiation of the employment contract after the revelation of the nature of the shock at the beginning of period 2, as a result of which agents do not care about the persistence of the shock.

\subsection{Case II: imperfect information, no labor adjustment costs}

We now introduce a role for the informational imperfection by assuming that the employer must set his period 2 level of employment in period 1 already. This is thus a case of commitment and implies that when the employer picks his level of employment for periods 1 and 2, he does not know yet whether the productivity shock $\xi$ is going to persist or not. So in this setting the informational imperfection does bind: at the beginning of period $2 N_{2}$ is a state variable and cannot respond to the arrival of new information at the beginning of this period.

Now, the firm's surplus equals:

$$
F^{i m, 0}=(A+\xi)\left(N_{1}^{i m, 0}\right)^{\alpha}-w_{1}^{i m, 0} N_{1}^{i m, 0}+(A+\theta \xi)\left(N_{2}^{i m, 0}\right)^{\alpha}-w_{2}^{i m, 0} N_{2}^{i m, 0},
$$

where we have used the fact that our rational expectations assumption implies that $\mathbb{E}_{1}\left\{A_{2}\right\}=A+\theta \xi$. The superscript "im, 0 " indicates that this is the solution under imperfect information without labor adjustment costs.

The bargaining surplus for workers reads:

$$
W^{i m, 0}=N_{1}^{i m, 0}\left(w_{1}^{i m, 0}-b\right)+N_{2}^{i m, 0}\left(w_{2}^{i m, 0}-b\right)
$$

\footnotetext{
${ }^{9}$ Also note that the wage rates resulting from the bargaining process can be obtained by inserting the solutions (1) and (2) into the second first-order condition (" $W^{f}=F^{f}$ ").
} 
The first-order conditions (now requiring that $\partial S^{i m, 0} / \partial N_{1}^{i m, 0}=\partial S^{i m, 0} / \partial N_{2}^{i m, 0}=$ $\left.\partial S^{i m, 0} / \partial w_{1}^{i m, 0}=\partial S^{i m, 0} / \partial w_{2}^{i m, 0}=0\right)$, can then be shown to imply that:

$$
\begin{aligned}
& N_{1}^{i m, 0}=\left[\frac{\alpha(A+\xi)}{b}\right]^{\frac{1}{1-\alpha}} \\
& N_{2}^{i m, 0}=\left[\frac{\alpha(A+\theta \xi)}{b}\right]^{\frac{1}{1-\alpha}}
\end{aligned}
$$

Note that labor adjustment is still costless in this case, as the employer is free to set $N_{2}$ different from $N_{1}$.

\subsection{Case III: imperfect information, infinite labor adjust- ment costs}

To add labor adjustment costs to the model, we assume that there only exist twoperiod employment contracts and that additional hiring at the beginning of period 2 is prohibitively expensive. This is the limiting case of infinite, non-convex labor adjustment costs over the time period to which the informational imperfection applies (i.e. over periods 1 and 2). It implies that it is now no longer possible to negotiate a different labor contract for period 2, than the one that was agreed upon for period 1. Consequently, $N_{1}=N_{2}=N^{i m, \infty}$ and $w_{1}=w_{2}=w^{i m, \infty}$ (where the superscripts $i m, \infty$ indicate that these are the solutions under imperfect information with infinite labor adjustment costs). Using that $\mathbb{E}_{1}\left\{A_{2}\right\}=A+\theta \xi$, the firm's surplus equals:

$$
F^{i m, \infty}=(A+\xi)\left(N^{i m, \infty}\right)^{\alpha}-w^{i m, \infty} N^{i m, \infty}+(A+\theta \xi)\left(N^{i m, \infty}\right)^{\alpha}-w^{i m, \infty} N^{i m, \infty}
$$

Similarly, the surplus for the workers reads:

$$
W^{i m, \infty}=2 N^{i m, \infty}\left(w^{i m, \infty}-b\right)
$$

The first-order conditions accompanying the bargaining game $\left(\partial S^{i m, \infty} / \partial N^{i m, \infty}=\right.$ $\left.\partial S^{i m, \infty} / \partial w^{i m, \infty}=0\right)$ then imply that the employer sets his level of employment for 
both periods equal to:

$$
N_{1}^{i m, \infty}=N_{2}^{i m, \infty}=\left[\frac{\alpha\left(A+\frac{\theta+1}{2} \xi\right)}{b}\right]^{\frac{1}{1-\alpha}}
$$

Note from this expression that first-period hiring is increasing in the probability that the positive productivity shock is persistent, $\theta$ : after all, if it is highly likely that next period's productivity level will be high again, the employer decides to guard himself against this by hiring more employees in period 1 already as he cannot hire additional ones at the beginning of period 2 .

\subsection{Case IV: perfect information, infinite labor adjustment costs}

In this final case, firms do have perfect information on the persistence of shocks but face infinite labor adjustment costs. Here, we have to distinguish between two subcases: one in which employers know that the shock is fully persistent, and one in which employers know that the shock is purely transitory. The solutions to this case can be derived from Case III by substituting $\theta=1$ or $\theta=0$ respectively.

Subcase 1: Persistent shock $(\theta=1)$

Just inserting $\theta=1$ in (5) yields:

$$
N_{1}^{p, \infty}=N_{2}^{p, \infty}=\left[\frac{\alpha(A+\xi)}{b}\right]^{\frac{1}{1-\alpha}}
$$

where the superscript $p, \infty$ indicates that this is the level of employment arising under infinite labor adjustment costs in response to a fully persistent shock.

Subcase 2: Transitory shock $(\theta=0)$

In this case, inserting $\theta=0$ in (5) yields:

$$
N_{1}^{t, \infty}=N_{2}^{t, \infty}=\left[\frac{\alpha\left(A+\frac{1}{2} \xi\right)}{b}\right]^{\frac{1}{1-\alpha}}
$$


where the superscript $t, \infty$ refers to the fact that this is the solution under infinite labor adjustment costs in response to a purely transitory shock.

Together, eqs (6) and (7) show that the employer's behavior under infinite labor adjustment costs in the presence of imperfect information (represented by eq. (5)) is a weighted average between the corresponding solutions under perfect information. The particular weight placed on the two cases is the probability that the shock is persistent or not, $\theta$.

\section{Results}

Using the framework developed in the previous sections, we can now state the two main results of this paper. First of all, Proposition 1 shows that there exists an option value to waiting once there is imperfect information on the shock's persistence. An option value arises when there is a value to postponing decisions, so it can be calculated by subtracting the expected value under pre-commitment (Case II, in which we force the firm to set his second period employment level at the beginning of period 1 already (when there is still uncertainty on the nature of the shock)) from the expected value under flexibility (Case I, in which we allow the firm to make his second period hiring decision after observing the nature of the shock). Subsequently, Proposition 2 shows that imperfect information (and the accompanying option value) by itself is not enough to generate lagged labor adjustment. For that, it needs to be combined with labor adjustment costs.

Proposition 1 (Option value of waiting) In the presence of informational imperfections (i.e. as long as $\theta \in(0,1)$ ), having the opportunity to await the nature of the productivity shock has a positive option value.

Proof. The option value of waiting can be obtained by subtracting the expected value under pre-commitment (Case II) from the expected value under flexibility (Case I). The expected value for the employer under flexibility reads: 


$$
\begin{aligned}
V\left(N^{f}\right)= & (1+\theta)\left[(A+\xi)\left[\frac{\alpha(A+\xi)}{b}\right]^{\frac{\alpha}{1-\alpha}}-\left[\frac{(1+\alpha) b}{2 \alpha}\right]\left[\frac{\alpha(A+\xi)}{b}\right]^{\frac{1}{1-\alpha}}\right] \\
& +(1-\theta)\left[A\left[\frac{\alpha A}{b}\right]^{\frac{\alpha}{1-\alpha}}-\left[\frac{(1+\alpha) b}{2 \alpha}\right]\left[\frac{\alpha A}{b}\right]^{\frac{1}{1-\alpha}}\right]
\end{aligned}
$$

Similarly, the expected value for the employer under commitment reads:

$$
\begin{aligned}
V\left(N^{i m, 0}\right)= & (A+\xi)\left[\frac{\alpha(A+\xi)}{b}\right]^{\frac{\alpha}{1-\alpha}}-\left[\frac{(1+\alpha) b}{2 \alpha}\right]\left[\frac{\alpha(A+\xi)}{b}\right]^{\frac{1}{1-\alpha}} \\
+ & {\left[(A+\theta \xi)\left[\frac{\alpha(A+\theta \xi)}{b}\right]^{\frac{\alpha}{1-\alpha}}-\left[\frac{(1+\alpha) b}{2 \alpha}\right]\left[\frac{\alpha(A+\theta \xi)}{b}\right]^{\frac{1}{1-\alpha}}\right] }
\end{aligned}
$$

Subtracting (9) from (8) results in the following expression, representing the option value of waiting:

$$
\begin{aligned}
\Omega= & (1+\theta)\left[(A+\xi)\left[\frac{\alpha(A+\xi)}{b}\right]^{\frac{\alpha}{1-\alpha}}-\left[\frac{(1+\alpha) b}{2 \alpha}\right]\left[\frac{\alpha(A+\xi)}{b}\right]^{\frac{1}{1-\alpha}}\right] \\
& +(1-\theta)\left[A\left(\frac{\alpha A}{b}\right)^{\frac{\alpha}{1-\alpha}}-\left[\frac{(1+\alpha) b}{2 \alpha}\right]\left(\frac{\alpha A}{b}\right)^{\frac{1}{1-\alpha}}\right] \\
& -(A+\xi)\left[\frac{\alpha(A+\xi)}{b}\right]^{\frac{\alpha}{1-\alpha}}+\left[\frac{(1+\alpha) b}{2 \alpha}\right]\left[\frac{\alpha(A+\xi)}{b}\right]^{\frac{1}{1-\alpha}} \\
& -\left[(A+\theta \xi)\left[\frac{\alpha(A+\theta \xi)}{b}\right]^{\frac{\alpha}{1-\alpha}}-\left[\frac{(1+\alpha) b}{2 \alpha}\right]\left[\frac{\alpha(A+\theta \xi)}{b}\right]^{\frac{1}{1-\alpha}}\right]
\end{aligned}
$$

The equation for the option value has its roots at $\theta=0$ and $\theta=1$ (which is intuitive as there is no uncertainty at the endpoints). As second derivative of $\Omega$ with respect to $\theta$ is negative due to the concavity of the production function $(\alpha<1)$, the option value is strictly positive over the domain $\theta \in(0,1)$ by Rolle's theorem. 
$\Omega$ reaches its maximum for the value of $\theta$ at which the variance of the underlying process is maximized. Since we assumed a Bernoulli distribution, which has variance $\theta \cdot(1-\theta)$, the option value reaches its maximum at $\theta=\frac{1}{2}$ : at that value, the uncertainty about the persistence of the shock is maximized, and so is therefore the value of being able to wait.

Fig. 6 shows the option value for different values of $\theta$ and $\alpha$. Note that the option value also increases in $\alpha$ since a higher $\alpha$ implies a higher marginal product of labor and therefore a higher cost of guessing wrong.

The question now becomes whether this option value to waiting by itself is enough to generate lagged labor adjustment. To investigate the conditions under which a labor adjustment lag arises, we need to augment the model with a third period. After all, it is not possible to talk about a lag in a two period framework: in such a setup, lagged labor adjustment and muted labor adjustment are observationally equivalent.

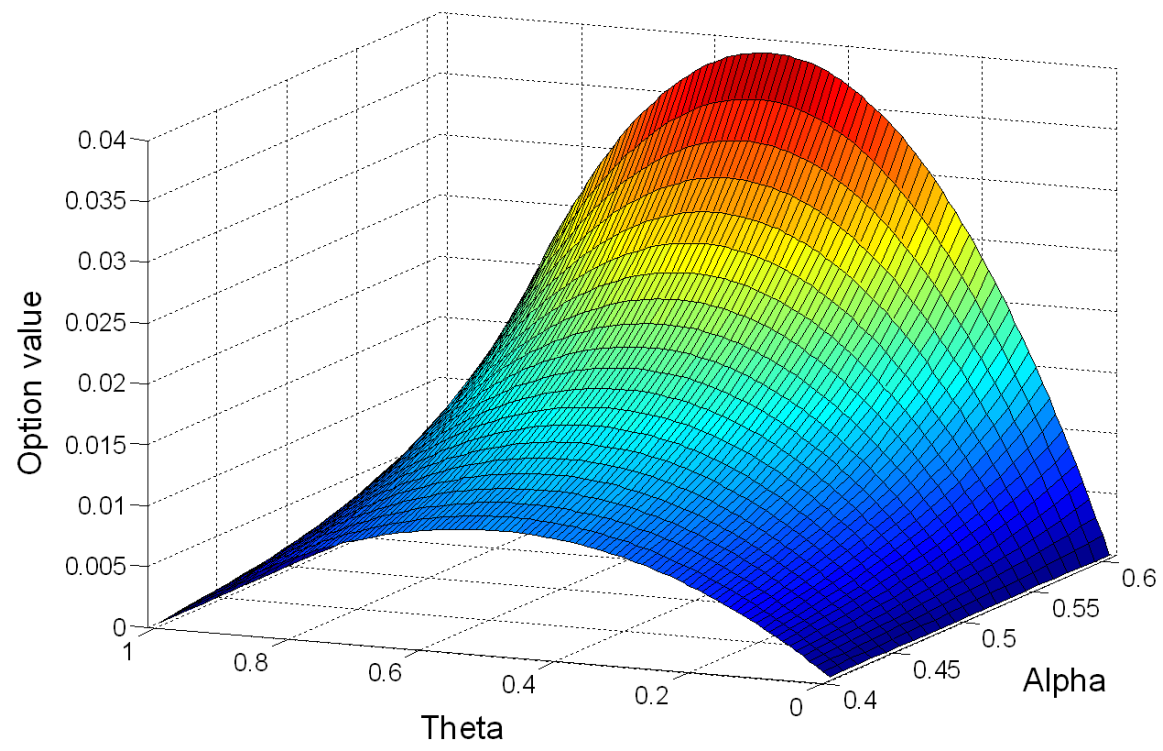

Fig. 6. Option value of waiting for the employer in the (alpha,theta)-space

In this respect, our two period setup allows for an easy addition of subsequent periods: when modeling labor adjustment costs in Section 5.3, we have already assumed that employment contracts last for two periods. If we in addition assume that 
uncertainty resolves over time by assuming that the nature of the shock (persistent or transitory?) always becomes clear at the beginning of the third period (which can be ensured by appropriately defining the length of a period), there is complete separability between the decisions for the first two periods and those for periods three and four. Consequently, the period 3 level of employment will be set according to eq. (6), which determines the level of employment set under perfect information when labor adjustment is costly $\left(N_{1}^{p, \infty}\right)$. Now we can define a labor adjustment lag after a positive productivity shock as a situation in which both $N_{1}, N_{2}<N_{3}$ (with $\left.N_{3}=N_{1}^{p, \infty}\right)$.

To see when this is the case, Table 1 compares the labor input choices for the different cases when the shock persists (i.e. for $\theta=1$ ). ${ }^{10}$ Note in this respect that persistence of a shock is a precondition to be able to speak of a jobless recovery. After all, if the shock to $A$ were only transitory, there would not be a recovery but only a temporary one-period blip in the data.

\begin{tabular}{lll} 
Case & \multicolumn{1}{c}{ Description } & \multicolumn{1}{c}{$N_{\theta=1}$} \\
\hline \hline$I$ & Full flexibility & $N_{1}^{f}=N_{2}^{f}\left(=N_{1}^{p, \infty}\right)$ \\
$I I$ & Imperfect info, costless labor adjustment & $N_{1}^{i m, 0}=N_{1}^{p, \infty}>N_{2}^{i m, 0}<N_{1}^{p, \infty}$ \\
$I I I$ & Imperfect info, costly labor adjustment & $N_{1}^{i m, \infty}=N_{2}^{i m, \infty}<N_{1}^{p, \infty}$ \\
$I V$ & Perfect info, costly labor adjustment & $N_{1}^{p, \infty}=N_{2}^{p, \infty}\left(=N_{1}^{f}\right)$
\end{tabular}

Table 1: Summary of cases

From this table, one can infer that only Case III (the situation in which information is imperfect and labor adjustment is costly) satisfies the definition of a labor adjustment lag. Hence, both elements are necessary to obtain this lag, as is formalized in the following proposition.

Proposition 2 (Labor adjustment lag) The combination of informational imperfections with non-convex labor adjustment costs leads to a lagged response of labor input to persistent productivity shocks.

\footnotetext{
${ }^{10}$ We thank an anonymous referee for suggesting this way of exposition to us.
} 
Proof. Compare labor input under infinite labor adjustment costs and imperfect information (eq. (5)), with first-period labor input under perfect information with labor adjustment costs (eq. (6)). Then, $\theta<1$ implies that $N_{1}^{i m, \infty}=N_{2}^{i m, \infty}<N_{1}^{p, \infty}$ in case of a positive productivity shock, while the reverse applies to a negative shock. Hence, labor adjustment costs and imperfect information on the persistence of the shock will make labor input respond more cautiously. However, after it has become clear that the shock is persistent at the beginning of period 3 , we effectively move to the perfect information case with costly labor adjustment (Case III). Consequently, $N_{3}=N_{1}^{p, \infty}$ and we have verified that this case satisfies the definition of a labor adjustment lag (namely a situation in which both $N_{1}, N_{2}<N_{3}$ ).

Jobless growth is thus only a temporary phenomenon: as uncertainty resolves labor input will eventually catch up following persistent shocks, but it will lag output around turning points (when there is uncertainty on the shock's persistence).

Comparing eqs (3) and (6) shows that the informational imperfection alone is not enough to generate a labor adjustment lag: for that it needs to be combined with labor adjustment costs. Also, eqs (6) and (7) show that non-convex labor adjustment costs alone are not sufficient to generate lagged labor adjustment either. In that case, firms either increase employment all the way (if they realize that a shock is persistent) or, if they know that the shock is only temporary, they set employment somewhere in between the level of employment chosen absent any shocks and the employment level they would have picked after a persistent shock of equal size. This shows that non-convex labor adjustment costs in isolation only lead to a muted labor input response (consistent with the result obtained by Bentolila and Bertola (1990)), but not to a delayed response. ${ }^{11}$

It is thus the combination of informational imperfections and non-convex labor adjustment costs that makes labor input lag the cycle.

\footnotetext{
${ }^{11}$ Do note that convex labor adjustment costs would generate lagged (or maybe it is better to speak of "gradual") labor adjustment - even in a completely deterministic setting. However, as noted before, empirical studies hardly ever find evidence for convexities in labor adjustment costs.
} 


\section{$7 \quad$ Why has the labor adjustment lag increased?}

Now that we have pointed at the existence of the labor adjustment lag and investigated its potential causes, the key question is: why has this lag increased since the 1980s? As shown in the previous section, a labor adjustment lag results from two ingredients: labor adjustment costs and imperfect information on the persistence of shocks. To answer the question why the lag went up in the 1980s, it is therefore natural to look for changes in these two ingredients that occurred around that time.

\subsection{Labor adjustment costs}

As documented by Autor et al. (2007), labor adjustment costs indeed changed during the 80s: in that decade, most US states adopted wrongful discharge protection. These common-law protections restricted employers' abilities to layoff workers "at will", which had always been possible in the US since the adoption of the so-called "employment-at-will" doctrine in the 1930s. This change in the legal environment generated a flood of litigation and increased the (potential) cost of laying off workers - thereby making employers more careful to do so.

The data also point at another important development, displayed in Fig. 7: this figure shows that all pre-1990 increases in unemployment where at least partially caused by an increase in temporary layoffs. However, since the 1980s, almost all cyclical variation in the temporary layoff rate has vanished and unemployment rises exclusively due to permanent layoffs in recessions.

When employers are able to layoff workers only temporarily, worker-firm matches stay intact and the whole option value of waiting argument applies to a much lesser extent: the firm still knows the worker and can reactivate him by a simple phone call, rather than going through the costly and uncertain process of hiring a new worker. In the early sample, employers thus basically passed the option value of waiting risk on to the US tax payer, as they would just push an employee into the welfare system whenever the economy started to lose momentum, without paying firing taxes that fully internalized this externality. 


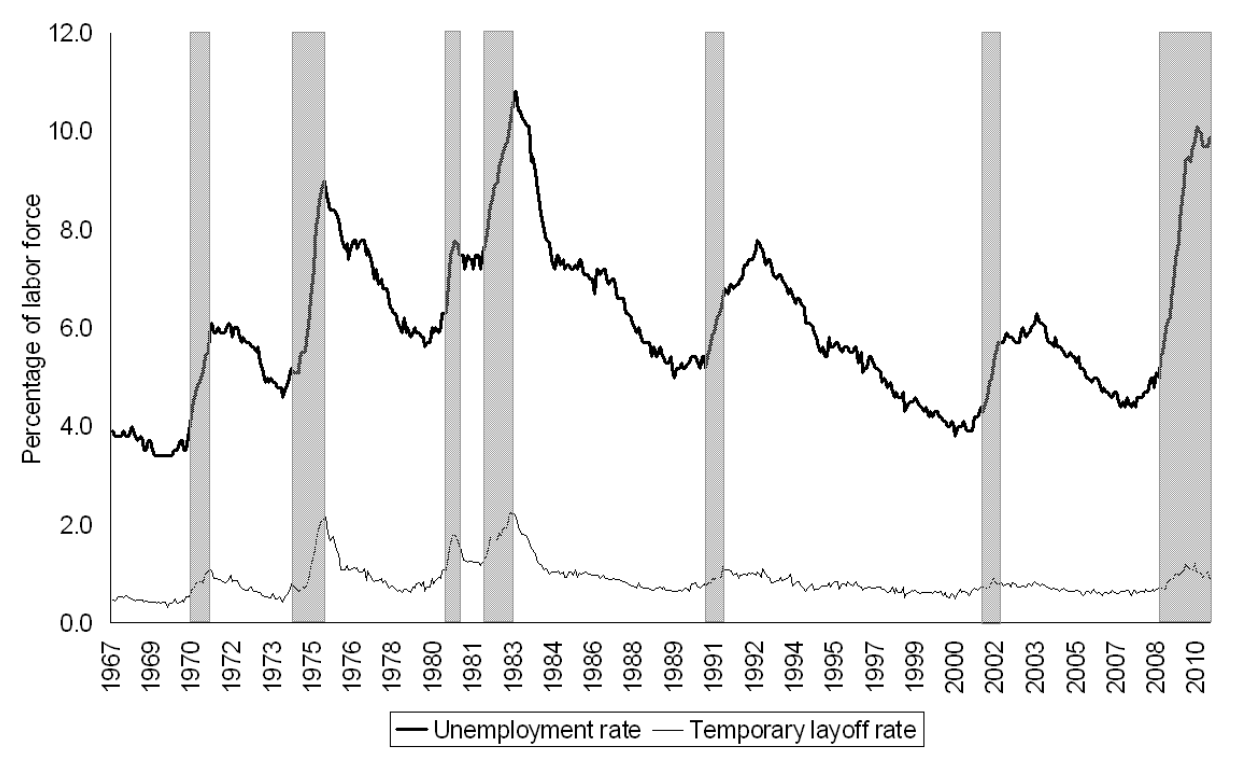

Fig. 7. Temporary layoff- and unemployment rates (data are from the BLS).

Shaded areas correspond with the NBER recession dates.

US policy makers realized this in the early 80s (see the introduction of Burdett and Wright (1989)) and increased the reliance upon "experience rating" in response (Topel, 1990). Under a system of experience rating, the height of the firing tax a firm has to pay to layoff workers at time $t$ depends positively upon the number of workers a firm has laid off in the recent past. Consequently, a system of experience rating strongly reduces firms' incentives to layoff workers temporarily (Card and Levine, 1994). As a result, it became less attractive for US firms to pass the option risk on to the tax payer and most worker-firm matches that were destroyed in the last two recessions (as well as in the current one), were destroyed permanently. These matches could only be restored by overcoming the option value of waiting-barrier during the subsequent upturn - thereby potentially contributing to lagged labor adjustment.

\subsection{Clarity of information}

Another possible reason why the labor adjustment lag could have gone up, is by an increase in the uncertainty about the persistence of shocks. 
There is indeed evidence that this type of uncertainty, which has to be distinguished from volatility, has increased since the 1980s: ${ }^{12}$ Campbell (2007) notes, by looking at the Survey of Professional Forecasters, that macroeconomic predictability has declined significantly since 1984. Similar findings are reported by Schuh (2001), D'Agostino, Giannone and Surico (2006) and Tulip (2005). The latter notes that 'the predictable component of output growth has virtually disappeared. Although output was highly variable in the 1970s and early 1980s, most of this variation was predicted. In contrast, variations since the late 1980s have been surprises' (Tulip, 2005: p. 12). Campbell (2007: p. 199) on his turn reports that 'the information content of current conditions has (...) declined' since 1984, which is consistent with an increase in the confusion about the persistence of shocks. ${ }^{13}$

There is also evidence that firm-specific uncertainty has increased over the last three decades: Campbell et al. (2001) report that firm-level volatility of annualized daily stock returns of US firms increased in the 80s and 90s compared to the $60 \mathrm{~s}$ and 70s, whereas market-level volatility remained roughly constant over this time period. A similar conclusion is reached by Comin and Philippon (2006), who besides analyzing stock returns - also look at sales volatility and credit spreads of US firms.

To sum all evidence up, it seems that transitory and permanent shocks have become more difficult to distinguish from each other since the 1980s. In terms of our

\footnotetext{
${ }^{12} \mathrm{~A}$ variable can be highly volatile, but perfectly predictable. Consider for example the seasonal fluctuations in output that account for about 85 percent of total output variability, but which are almost perfectly predictable (Beaulieu and Miron, 1992).

${ }^{13}$ In this respect it is also interesting to note that the lag with which the NBER Business Cycle Dating Committee announces peaks and troughs has doubled over the years: the pre-1990 turning points were announced with an average lag of 7.5 months, while this lag equals about 14 months for the post-1990 ones (see http://www.nber.org/cyclesmain.html for the announcement dates). Why all this has happened is still an open question that goes beyond the scope of this paper. It might just be due to "bad luck", while it is - somewhat paradoxically - also possible that this is a result of the increased communication of both monetary and real statistics over the years: Amador and Weill (2008) for example show that more public information on aggregate fundamentals can actually increase confusion and uncertainty about them - thereby leading to less accurate forecasts. The reason is that individuals put less weight on private information after public announcements (as the acquisition of information is costly), which, Amador and Weill show, can reduce the informational efficiency of the price system to such a large extent that uncertainty about fundamentals goes up. Morris and Shin (2005) and Wong (2008) develop similar arguments.
} 
two-period model this implies that $\theta$ has moved towards $\frac{1}{2}$. Consequently, the option value of waiting has increased and employers simply have to wait longer (in order to obtain more signals) before they can make well-informed decisions.

\section{Is the labor adjustment lag the answer to some macroeconomic puzzles?}

An increase in the lag with which labor input is adjusted in response to structural shocks to GDP has substantial implications for both labor productivity and the volatility of output. In this section we will describe the theoretical predictions with respect to these variables and show that these predictions are consistent with the puzzling behavior these variables have displayed in practice since the 1980s.

\subsection{The Great Moderation}

The volatility of several macroeconomic variables (in particular that of output) has reduced significantly since the 1980s. This observation is referred to as "the Great Moderation". The fact that the timing of the Great Moderation (often estimated to lie somewhere around 1984; cf. McConnell and Perez-Quiros (2000)) roughly coincides with the increase in the labor adjustment lag (which lies in between the 1982 and the 1990/1 recessions), suggests that the two developments may be related. The explanation could be as follows. Before the 1990/1 recession, a persistent positive productivity shock would increase output for two distinct reasons: first, directly because productivity went up, and, second, indirectly because labor input would soon follow. After all, before the 1990s, the cycles for productivity and labor input stood roughly in phase as a result of which they amplified each other - thereby leading to a rather high volatility in output.

However, since the mid-1980s labor input responds with a greater lag to structural

shocks (see the IRFs in Section 2.2 of this paper and the evidence in Stiroh (2009), who reports that the contemporaneous correlation between productivity shocks and 
labor input has declined since 1984). Consequently, these cycles do not amplify each other anymore as a result of which output follows a much more muted path.

But are the lagged labor input response, and the associated decrease in the contemporaneous correlation between output and labor input, quantitatively important enough to explain the observed reduction in output volatility? To get an idea of the answer to this question, we take a basic RBC-model where the representative household faces the standard optimization problem.

$$
\begin{aligned}
& \max _{\left\{c_{t}, h_{t}, k_{t+1}\right\}_{t=0}^{\infty}} \mathbb{E}_{0} \sum_{t=0}^{\infty} \beta^{t}\left[\frac{c_{t}^{1-\nu}-1}{1-\nu}+\frac{\vartheta}{1-\eta}\left[\left(1-h_{t}\right)^{1-\eta}-1\right]\right] \\
& \text { s.t. } k_{t+1}=(1-\delta) k_{t}+\exp \left(z_{t}\right) k_{t}^{\alpha} h_{t}^{1-\alpha}-c_{t} \\
& z_{t+1}=\rho z_{t}+\varepsilon_{t+1}, \quad \varepsilon_{t} \sim \mathcal{N}\left(0, \sigma^{2}\right)
\end{aligned}
$$

The associated first-order conditions read:

$$
\begin{aligned}
\partial c_{t} & : c_{t}^{-\nu}=\lambda_{t} \\
\partial h_{t} & : \vartheta\left(1-h_{t}\right)^{-\eta}=(1-\alpha) \lambda_{t} \exp \left(z_{t}\right) k_{t}^{\alpha} h_{t}^{-\alpha} \\
\partial k_{t+1} & : \lambda_{t}=\beta \mathbb{E}_{t}\left\{\lambda_{t+1}\left[\alpha \exp \left(z_{t+1}\right) k_{t+1}^{\alpha-1} h_{t+1}^{1-\alpha}+(1-\delta)\right]\right\},
\end{aligned}
$$

where $\lambda_{t}$ measures the time $t$ marginal utility of wealth.

The model (in which each period corresponds to one quarter) is calibrated using standard values in the literature (see Table 2). The preference parameter for leisure $\vartheta$ is set equal to 3.48 , to match the fact that US agents spend about $20 \%$ of their available time on market production. Finally, the standard deviation of the productivity shock $(\sigma)$ is set such that the standard deviation of the simulated series for output matches its US pre-1984 data equivalent of 0.02 (as reported by Galí and Gambetti (2009)).

However, such a standard RBC-model does not feature lagged labor adjustment. This can be seen from the fact that there is almost perfect comovement between labor input and the business cycle: in the standard RBC-model described above $\operatorname{corr}(y, h)=0.9802$, whereas the post-1984 US data imply a value of 0.8148 . Since our 
only purpose here is to demonstrate that the decreased correlation between output and labor input has some potential to explain the reduction in output volatility, we decrease this correlation by introducing the labor adjustment lag in a very ad hoc manner, namely by only including lagged labor input in the production function.

\begin{tabular}{lll} 
Symbol & Interpretation & Value \\
\hline \hline$\alpha$ & Output elasticity of capital & 0.33 \\
$\beta$ & Quarterly discount rate & 0.99 \\
$\delta$ & Quarterly depreciation rate & 0.025 \\
$\eta$ & Labor supply elasticity & 1 \\
$\vartheta$ & Preference for leisure & 3.48 \\
$\nu$ & Coefficient of relative risk aversion & 1 \\
$\rho$ & AR-coefficient on productivity process & 0.95 \\
$\sigma$ & Standard deviation of productivity shock & 0.015
\end{tabular}

Table 2: Calibration

As argued in Hagedorn and Manovskii (2010), such a lag is natural if it takes firms time to adjust labor input (as under frictional labor adjustment), or if it takes firms time to be sure that aggregate productivity has changed (related to our notion of imperfect information). Total output then follows $y_{t}=\exp \left(z_{t}\right) k_{t}^{\alpha} h_{t-i}^{1-\alpha}$, where $i$ is the lag-length. As a result, first-order conditions (11) and (12) change into:

$$
\begin{aligned}
\partial h_{t} & : \quad \vartheta\left(1-h_{t}\right)^{-\eta}=(1-\alpha) \beta^{i} \lambda_{t+i} \exp \left(z_{t+i}\right) k_{t+i}^{\alpha} h_{t}^{-\alpha} \\
\partial k_{t+1} & : \quad \lambda_{t}=\beta \mathbb{E}_{t}\left\{\lambda_{t+1}\left[\alpha \exp \left(z_{t+1}\right) k_{t+1}^{\alpha-1} h_{t+1-i}^{1-\alpha}+(1-\delta)\right]\right\}
\end{aligned}
$$

The implications for the standard deviation of output are shown in Fig. 8. As the figure shows, a labor adjustment lag indeed reduces output volatility. Interestingly, when the model's correlation between output and labor input approximately matches its post-1984 data equivalent of 0.8148 at $i=8$, the model's standard deviation of output roughly matches its post-1984 data equivalent as well (equal to 0.0094 (Galí and Gambetti, 2009) and indicated by the dashed line in Fig. 8). The reduced contemporaneous correlation between output and labor input (brought about by an 
increase in the labor adjustment lag) is thus quantitatively able to explain the Great Moderation in a standard RBC-setting. Obviously, this is only a reduced form way to bring the correlation between output and labor input down. Constructing a microfounded model that has this implication lies beyond the scope of this paper, but the reported results suggest that this could be a fruitful topic for further research.

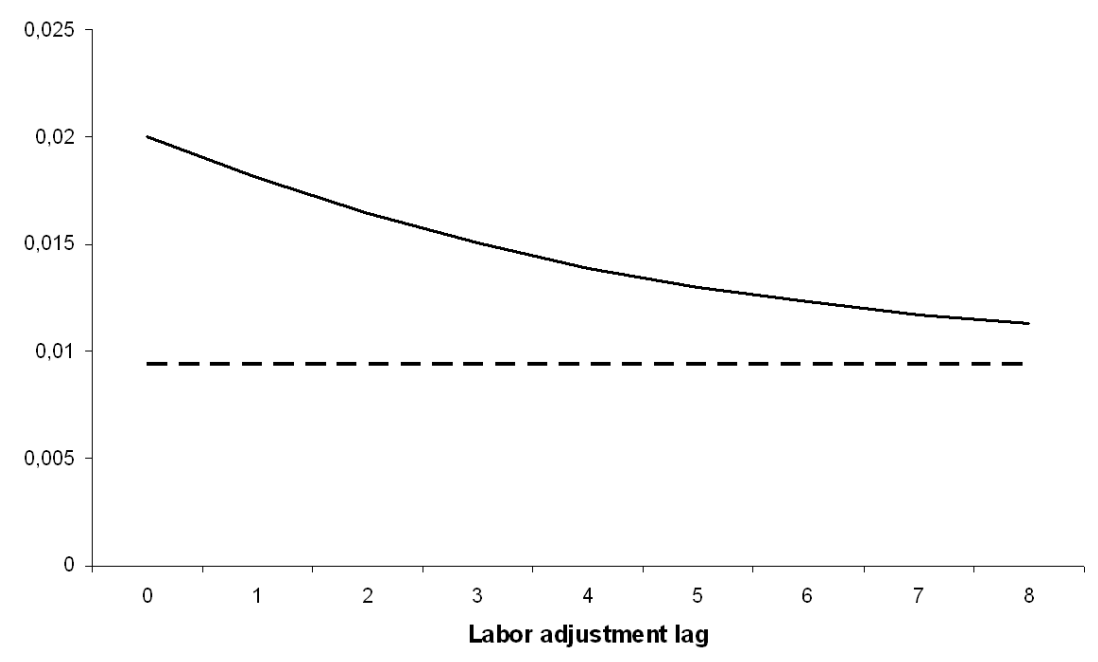

Fig. 8. Standard deviation of output as function of the labor adjustment lag

Relating our finding that the labor adjustment lag has some potential to explain the Great Moderation to our discussion in Section 7, suggests two novel hypotheses on the sources of the Great Moderation. First, it may be a result of higher labor adjustment costs since the 1980s brought about by the increased importance of experience rating combined with the weakening of the employment-at-will doctrine.

Second, and contrasting with the "good luck hypothesis" advocated by among others Stock and Watson (2005), our results point toward the possibility of a "bad luck hypothesis": potentially because of bad luck, shocks have been surrounded by more noise on their persistence since the mid-80s, as a result of which a given shock has induced smaller contemporaneous fluctuations in factor inputs - and hence output - since. Note that - as the good luck hypothesis - ours also conditions on the size of the shocks and thus does not rule out heavy business cycle fluctuations since the 1980s (a claim that is pretty unwarranted in the light of the recent "Great Recession"); it only 
implies that a given persistent shock leads to greater macroeconomic fluctuations if the fact that the shock is persistent, is realized upon impact.

Note that this view is also able to give an explanation for the paradoxical situation that the reduction in macroeconomic volatility seems to have been accompanied by a decrease in predictability: in our hypothesis, the decrease in predictability has actually caused the reduction in macroeconomic volatility!

\subsection{The cyclicality and volatility of labor productivity}

The volatility and cyclicality of US labor productivity have also shown puzzling behavior since the mid-1980s: first, the procyclicality of labor productivity has dropped over the years. In particular, the correlation between output and labor productivity went down from its pre-1984 value of 0.87 to a significantly lower post-1984 value of 0.72 (Galí and Van Rens, 2008). Second, the standard deviation of labor productivity relative to that of output is higher in the post-1984 sample than it was in the pre-1984 sample (went up from 0.45 to 0.55; Galí and Gambetti (2008)).

As labor productivity is nothing more than an accounting identity (by definition it equals output divided by labor input), simple arithmetic already implies that an increase in the lag between the cycles for output and labor input should have implications for its behavior. This can be shown most easily by conducting a simple sine-experiment, similar to the one in Wen (2004). First, assume that the cyclical component of the employment series follows:

$$
n_{t}=\sin (\omega t)
$$

Similarly, the cyclical component of output is assumed to be generated by:

$$
y_{t}=\mu \sin (\omega t+\phi)
$$

Here, the parameter $\mu$ allows us to capture the empirical fact that output is slightly more volatile than employment, while setting $\phi \neq 0$ results in a labor input lag. 
Now consider Fig. 9, which is generated by setting $\omega=0.2$ and $\phi=0$ such that output and labor input are in phase with each other, which approximates the situation before the 1990/1 recession. We set $\mu$ equal to 1.2 such that the standard deviation of employment relative to that of output roughly matches its empirical counterpart of 0.85 .

Next to the series for output and employment, Fig. 9 also shows the implied behavior of labor productivity $p \equiv y-n$. As can be seen from the figure, labor productivity is perfectly procyclical, i.e. $\operatorname{corr}(y, p)=1$.

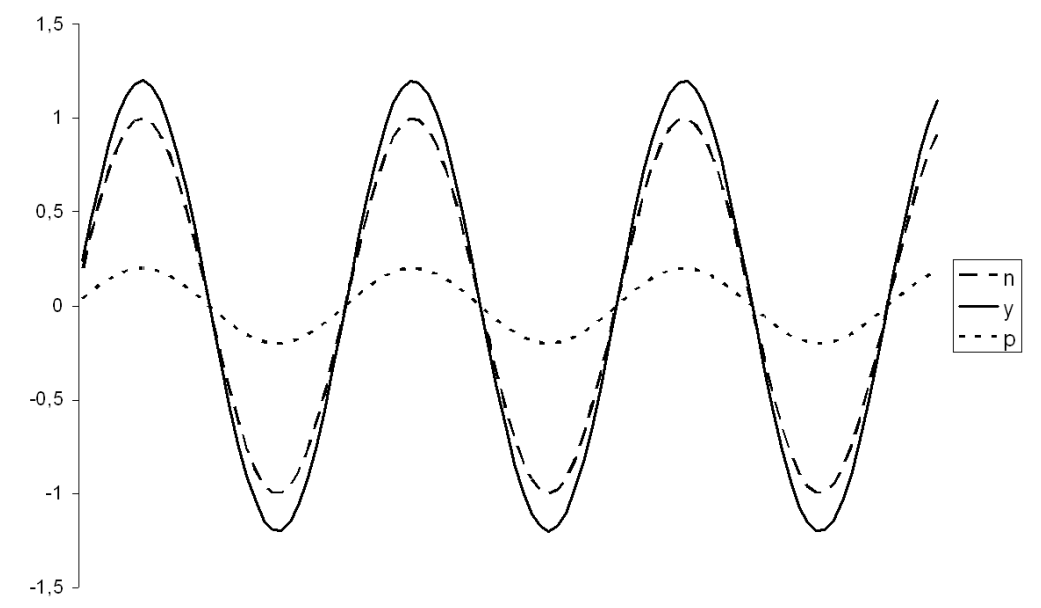

Fig. 9. Cyclicality without labor adjustment lag

Next, we approximate the situation after 1984 by introducing a labor input lag by setting $\phi>0$, say equal to 0.5 . As can be seen from Fig. 10, this simple experiment indeed predicts that the introduction of the lag has important consequences for the behavior of labor productivity: in particular, the cyclicality of labor productivity goes down (in this case $\operatorname{corr}(y, p)=0.58$ ), while the volatility of labor productivity relative to that of output goes up - exactly in line with what the data show. ${ }^{14}$

\footnotetext{
${ }^{14}$ Note that we can match the observed decline in the correlation between output and labor input exactly by setting $\phi=0.115$ to approximate the situation before 1984 and picking $\phi=0.22$ to capture the situation after.
} 


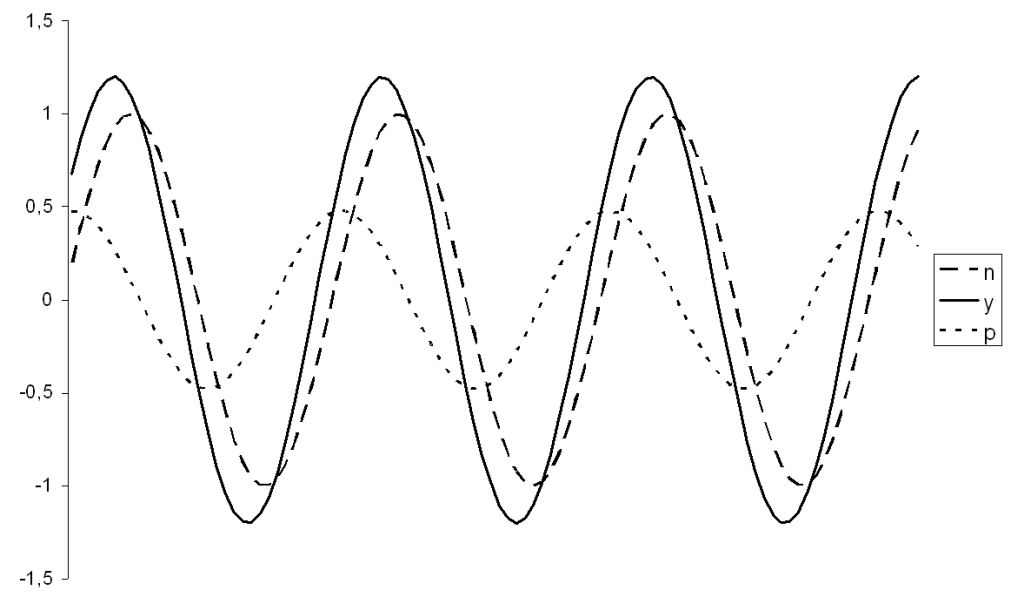

Fig. 10. Cyclicality with labor adjustment lag

\section{Conclusion}

We have presented evidence that the lag with which labor input reacts to structural economic shocks went up in the 1980s, thereby bringing jobless recoveries and recessions that were relatively job preserving to the US economy. Using a real option model, this lagged response is shown to be optimal in a setting where labor input is costly to adjust and where employers are uncertain about the persistence of shocks that drive the business cycle. Each factor in isolation is shown not to be enough to produce a labor adjustment lag.

We also show that the two factors necessary to generate a labor adjustment lag, both increased in empirical importance around the time the lag went up. For example, since the early 1980s the use of temporary layoffs has been discouraged by US government policy - thereby leading to worker-firm break-ups that are of a more permanent nature and hence more difficult to restore. In addition, macroeconomic predictability has shown a remarkable decline since the mid-80s, suggesting that the clarity of information about the persistence of shocks has gone down. Both developments increase employers' incentives to postpone hiring and firing decisions that are costly to reverse and could thereby explain the increase in the labor adjustment 
lag. ${ }^{15}$

We finally show that the labor adjustment lag has the potential to explain two macroeconomic puzzles that characterize US data since the mid-1980s. First, it is able to explain the reduction in the procyclicality of labor productivity that has kicked in over this period. Regarding the simultaneous reduction in output volatility, we show that this can be explained by the fact that agents have become slower in adjusting their labor input in response to driving shocks. Consequently, the exogenous shock-part and the endogenous factor input-part of the production function are no longer in phase with each other, as a result of which they amplify each other less than they did before, thereby leading to smaller fluctuations in output. This view sheds a new light on the paradoxical situation that the reduction in macroeconomic volatility has been accompanied by a decrease in predictability: we show that the decline in predictability might have actually caused the reduction in macroeconomic volatility.

In this respect, this paper also points at several directions for future research. For example, why exactly has macroeconomic predictability come down? Is this just a result of bad luck or is there a link with the change in the conduct of monetary policy since the 1980s? And will predictability remain low in the future or will it increase again? We hope to answer these questions in future research.

\section{References}

Aaronson, D., Rissman, E.R. , and Sullivan, D.G. (2004), Can sectoral reallocation explain the jobless recovery?, Federal Reserve Bank of Chicago Economic Perspectives, QII: 36-49.

\footnotetext{
${ }^{15}$ Both factors can also explain the simultaneous increase in the importance of temporary employment in adjusting labor input (documented in Peck and Theodore (2007)): because the aforementioned developments make firms less eager to commit to any decisions that are costly to reverse, they are now willing to make use of temp agencies that charge fees of 25 percent or more of the wage. Essentially, these agencies have thus stepped into the space created by the greater value employers attach to remaining flexible since the 1980s. Also see the discussion in Dixit and Pindyck (1994, p.15-16).
} 
Amador, M. and Weill, P.O. (2008), Learning from prices: public communication and welfare, NBER Working Paper No. 14255.

Andolfatto, D. and MacDonald, G. (2004), Jobless recoveries, Mimeo, Simon Fraser University.

Autor, D.H., Kerr, W.R. , and Kugler, A.D. (2007), Does employment protection reduce productivity? Evidence from US states, Economic Journal, 117, 189-217.

Bachmann, R. (2009), Understanding jobless recoveries, Mimeo, Yale University.

Beaulieu, J.J. and Miron, J.A. (1992), A cross country comparison of seasonal cycles and business cycles, Economic Journal, 102, 772-88.

Bentolila, S. and Bertola, G. (1990), Firing costs and labor demand: how bad is eurosclerosis?, Review of Economic Studies, 57, 381-402.

Blanchard, O.J. and Quah, D. (1989), The dynamic effects of aggregate demand and supply disturbances, American Economic Review, 79, 655-73.

Bloom, N. (2009), The impact of uncertainty shocks, Econometrica, 77, 623-85.

Burdett, K. and Wright, R. (1989), Unemployment insurance and short-time compensation: the effects on layoffs, hours per worker, and wages, Journal of Political Economy, 97, 1479-96.

Campbell, S.D. (2007), Macroeconomic volatility, predictability, and uncertainty in the great moderation: evidence from the survey of professional forecasters, Journal of Business \& Economic Statistics, 25, 191-200.

Campbell, J.Y., Lettau, M., Malkiel, B.G., and Xu, Y. (2001), Have individual stocks become more volatile? An empirical exploration of idiosyncratic risk, Journal of Finance, 56, 1-43.

Card, D. and Levine, P.B. (1994), Unemployment insurance taxes and the cyclical and seasonal properties of unemployment, Journal of Public Economics, 53, 1-29.

Christiano, L.J., Eichenbaum, M., and Vigfusson, R. (2003), What happens after a technology shock?, NBER Working Paper No. 9819.

Comin, D. and Philippon, T. (2005), The rise in firm-level volatility: causes and consequences, in M. Gertler and K.S. Rogoff (eds) NBER Macroeconomics Annual, MIT Press, Cambridge, MA.

D'Agostino, A., Giannone, D., and Surico, P. (2006), (Un)predictability and 
macroeconomic stability, ECB Working Paper No. 605.

Dixit, A.K. and Pindyck, R.S. (1994), Investment under Uncertainty, Princeton University Press, Princeton, NJ.

Dowrick, S. (1989) Union-oligopoly bargaining, Economic Journal, 99, 1123-1142.

Francis, N. and Ramey, V.A. (2009), Measures of per capita hours and their implications for the technology-hours debate, Journal of Money, Credit and Banking, 41, 1071-97.

Galí, J. (1999), Technology, employment, and the business cycle: do technology shocks explain aggregate fluctuations?, American Economic Review, 89, 249-71.

Galí, J. and Gambetti, L. (2009), On the sources of the great moderation, American Economic Journal: Macroeconomics, 1, 26-57.

Galí, J. and Van Rens, T. (2008), The vanishing procyclicality of labor productivity and the great moderation, Mimeo, Universitat Pompeu Fabra.

Gertler, M., Sala, L., and Trigari A. (2008), An estimated monetary DSGE model with unemployment and staggered nominal wage bargaining, Journal of Money Credit and Banking, 40, 1713-64.

Groshen, E.L. and Potter, S. (2003), Has structural change contributed to a jobless recovery, Current Issues in Economics and Finance, 9, 1-7.

Hagedorn, M. and Manovskii, I. (2010), Productivity and the labor market: comovement over the business cycle, International Economic Review, forthcoming.

Hamermesh, D.S. and Pfann, G.A. (1996), Adjustment costs in factor demand, Journal of Economic Literature, 34, 1264-92.

Koenders, K. and Rogerson, R. (2005), Organizational dynamics over the business cycle: a view on jobless recoveries, Federal Reserve Bank of St. Louis Review, 87, $555-79$.

McConnell, M.M. and Perez-Quiros, G. (2000), Output fluctuations in the United States: what has changed since the early 1980s?, American Economic Review, 90, 1464-76.

Morris, S. and Shin, H. (2005), Central bank transparency and the signal value of prices, Brookings Papers on Economic Activity, 2, 1-43.

Peck, J. and Theodore, N. (2007), Flexible recession: the temporary staffing in- 
dustry and mediated work in the United States, Cambridge Journal of Economics, 31, 171-92.

Pissarides, C.A. (2000), Equilibrium Unemployment Theory, MIT Press, Cambridge, MA.

Schuh, S. (2001), An evaluation of recent macroeconomic forecast errors, New England Economic Review, January/February, 35-56.

Stiroh, K.J. (2009), Volatility accounting: a production perspective on increased economic stability, Journal of the European Economic Association, 7, 671-96.

Stock, J.H. and Watson, M.W. (2005), Understanding changes in international business cycle dynamics, Journal of the European Economic Association, 3, 968-1006.

Topel, R.H. (1990), Financing unemployment insurance: history, incentives, and reform, in W.L. Hansen and J.F. Byers (eds) Unemployment Insurance, University of Wisconsin Press, Madison, WI.

Tulip, P. (2005), Has output become more predictable? Changes in Greenbook forecast accuracy, Finance and Economics Discussion Series 31.

Van Rens, T. (2004), Organizational capital and employment fluctuations, Mimeo, Universitat Pompeu Fabra.

Van Wijnbergen, S. (1985), Trade reform, aggregate investment and capital flight: on credibility and the value of information, Economics Letters, 19, 369-72.

Wen, Y. (2004), What does it take to explain procyclical productivity?, Contributions to Macroeconomics, 4, 1-38.

Wong, J. (2008), Information acquisition, dissemination, and transparency of monetary policy, Canadian Journal of Economics, 41, 46-79. 